\title{
Effect of the Synthetic Inhibitor Tosylamino- Phenylethyl-Chloromethylketone on Chemotactic Peptide Receptor Activation and Superoxide Production in Human Neutrophils
}

\author{
SUSANNE SUTER, P.D. LEW, AND F. A. WALDVOGEL \\ Department of Pediatrics and the Division of Infectious Diseases, Department of Medicine, University Hospital, \\ Geneva, Switzerland
}

\begin{abstract}
It was previously shown that inhibitors such as tosylamido-phenylethyl-chloromethylketone (TPCK) inhibit superoxide production by human neutrophils. These studies suggested that a chymotrypsin-like protease inhibited by TPCK was involved in the activation of the neutrophils oxidative system. In this study, we attempted to define the step in cellular activation and/or cell function inhibited by TPCK. TPCK $10^{-5} \mathrm{M}$ did not inhibit the following early events thought to be involved in the activation of oxidase. 1) f-met-leu-phe-induced activation of phospholipase $\mathrm{C}$ assessed by the production of inositoltris-phosphate (IP3), 2) f-met-leu-phe-induced membrane potential changes, 3 ) f-met-leu-phe-induced increase in free cytosolic calcium, and 4) phorbol-myristate acetate-induced protein phosphorylation in ${ }^{32} \mathrm{P}$ labeled neutrophils. We also showed that TPCK $10^{-5} \mathrm{M}$ inhibited bactericidal activity of neutrophils on Staphylococcus aureus, whereas it did not inhibit the ingestion rate of endotoxin-coated Oil red $O$ particles. We conclude that 1 ) TPCK at the concentration of $10^{-5} \mathrm{M}$ inhibits superoxide production but not ingestion of Oil red $O$ particles and 2) TPCK inhibits superoxide production at a step distal from calcium mobilization and protein phosphorylation. Radiolabeled TPCK may therefore be a useful tool to study, whether a protease is involved in the activation of the oxidative system distal to second messenger generation. (Pediatr Res 20: 848-852, 1986)
\end{abstract}

\section{Abbreviations}

DMSO, dimethylsulfoxide

Di-O-C3(5), 3-3'-dipentyl-oxycarbo cyanine iodide

FMLP, f-met-leu-phe

IP3, inositoltrisphosphate

ORO particles, endotoxin coated Oil red O-particles PMA, phorbol-myristate acetate

TPCK, tosylamino-phenylethyl-chloromethyl-ketone

One of the most important mechanisms by which neutrophil granulocytes mediate bacterial killing is the generation of oxi-

Received January 31, 1986; accepted April 23, 1986.

Reprint requests should be addressed to Dr. Susanne Suter, Clinique Universitaire de Pédiatrie, 1211-Geneva 4, Switzerland.

This work was supported by Grants 3.816-0.84 and 3.990-0.84 of the Swiss National Research Foundation. P.D.L is a recipient of a Max Cloétta Caree Development Award. dants such as $\mathrm{O}_{2}^{-}, \mathrm{OH}^{-}$, and $\mathrm{H}_{2} \mathrm{O}_{2}$ (1). The precise nature of the enzyme system producing these molecules remains unknown, as well as the mechanism of its activation. Results from studies with inhibitors and substrates for chymotrypsin-like proteases have suggested that protease(s) may be involved in the activation and activity of the oxidative system $(2,3)$. In one of these studies, the kinetics of inhibition of superoxide production of neutrophils by TPCK have been well defined (3). The conclusion of this study was that TPCK inhibits superoxide production by inhibiting a chymotrypsin-like protease at the neutrophil surface, which may play a role in the activation of the oxidative system, but the precise step at which TPCK inhibits superoxide production was not defined. Inhibition of superoxide production by TPCK could occur at several steps of cell activation and/or cell function. In the process of neutrophil activation, stimulation of a chemotactic receptor on the cell surface leads to activation of phospholipase $\mathrm{C}$ (4) and subsequently breakdown of membrane phosphoinositides. Thereby, two second messengers are generated: IP3 (5), which mobilizes free cytosolic calcium (4), and diacylglycerol, which is thought to activate protein kinase $\mathrm{C}(6)$. Once activated, protein kinase $\mathrm{C}$ phosphorylates neutrophil proteins $(10,11)$, and both, the rise in free cytosolic calcium and activation of protein kinase $\mathrm{C}$ are required to initiate cell function $(5$, 7,8 ). Another event occurring early during cell activation is the depolarization of the neutrophil membrane (9).

In this study, we decided to define conditions, in which the potential unspecific effects of TPCK (4) were minimal and subsequently, to determine the level at which TPCK inhibits receptor mediated superoxide production.

\section{MATERIALS AND METHODS}

Sources or reagents. TPCK, zymosan, Cytochrome C, FMLP, PMA, ORO, and phenylmethylsulfonylfluoride were from Sigma Co, St. Louis, MO. LPS P Escherichia coli 026 B6 was from Difco Laboratories, Detroit, MI. Pertussis toxin was from List Biological Laboratories Inc. Cambell, CA. Myo- $\left(2-{ }^{3} \mathrm{H}\right)$ inositol and quin2 acetoxymethylester (quin2/AM) was supplied by Amersham, England. Dextran T 500 and Ficoll-Hypaque was obtained from Pharmacia Fine Chemicals, Uppsala, Sweden. DIO-C ${ }^{3}(5)$ was from Molecular Probes Inc., Junction City, OR. 4Methylumbelliferyl substrates were from Koch Laboratories, Haverhill, England. RPMI medium 164D was from Amimed AG, Basel, Switzerland. All other reagents used were of analytical grade.

Preparation of neutrophils. Neutrophils were prepared from fresh citrate blood from healthy adult volunteers. They were purified by dextran sedimentation followed by centrifugation through a Ficoll layer as described previuosly (10) and contami- 
nating erythrocytes were removed by hypotonic lysis. The neutrophils were then suspended in a medium called calcium medium containing $138 \mathrm{mM} \mathrm{NaCl}, 6 \mathrm{mM} \mathrm{KCl}, 1 \mathrm{mM} \mathrm{MgSO}_{4}, 1,1$ $\mathrm{mM} \mathrm{CaCl}_{2}, 100 \mu \mathrm{M}$ EGTA, $1 \mathrm{mM} \mathrm{NaHPO}$, $5 \mathrm{mM} \mathrm{NaHCO}$, $5,5 \mathrm{mM}$ glucose, and $20 \mathrm{mM}$ Hepes, $\mathrm{pH}$ 7.4. The so-called calcium-free medium is identical to this medium, without $\mathrm{CaCl}_{2}$ and with addition of $1 \mathrm{mM}$ EGTA.

Superoxide production was measured continuously in a double beam spectrophotometer, thermostated at $37^{\circ} \mathrm{C}$ as previously described (11). Data are presented as nmol $\mathrm{O}^{-2}$ produced per $10^{6}$ neutrophils per min. The stimuli used to assess superoxide production by neutrophils were FMLP, PMA, and opsonized zymosan, which was prepared as previously described (12).

Phagocytic bactericidal assay. This assay was performed as previously described (13). Briefly, the killing of Staphylococcus aureus strain Wood 46 by isolated neutrophils in a medium containing $10 \%$ pooled human serum was assessed after $60 \mathrm{~min}$. Surviving intra- and extracellular bacteria were quantitatively determined after osmotic lysis of neutrophils with distilled water, serial dilutions of the samples, and plating on Muller Hinton agar to determine colony forming units. A control containing heat inactivated human serum was always run simultaneously. The effect of TPCK on the growth in vitro of $S$. aureus Wood 46 was also assessed simultaneously.

Phagocytic assay. The phagocytic assay was performed as previously described (14).

Degranulation. Neutrophils, $1.25 \times 10^{6}$, were suspended in 50 $\mu \mathrm{l}$ calcium medium containing $2.5 \mu \mathrm{g}$ cytochalasin B and warmed at $37^{\circ} \mathrm{C}$ for $5 \mathrm{~min}$. FMLP was added as a stimulus and the incubation continued for $5 \mathrm{~min}$. The reaction was stopped by rapid cooling on ice and centrifugation at $8000 \times \mathrm{g} / \mathrm{min}$. Vitamin $\mathrm{B}_{12}$ binding protein (as a marker of specific granules) and $\beta$ glucuronidase (as a marker of azurophile granules) were assayed in the supernatant. $\beta$-Glucuronidase was measured fluorimetrically (15) and vitamin $\mathbf{B}_{12}$-binding protein with a slight modification of the method of Kane (15). The release of granules is expressed as percent release in the supernatant/total enzyme content of neutrophils lysed with triton.

Depolarization. Changes in neutrophil membrane potential were measured in a fluorimetric assay using the membrane potential-sensitive cyanine dye $\mathrm{Di}-\mathrm{O}-\mathrm{C}_{3}$ as described by Seligman et al. (9). A Perkin-Elmer LS-3 spectrofluorimeter was used. Excitation and emission wavelength were 460 and $520 \mathrm{~nm}$, respectively. Di-O- $\mathrm{C}_{5}(3)$ was added at a final concentration of $10^{-7} \mathrm{M}$ into a cuvette containing calcium medium warmed continuously to $37^{\circ} \mathrm{C}$ and $5 \times 10^{5}$ neutrophils were added. The cell suspension was magnetically stirred. Depolarization is expressed as change in fluorescence.

Measurement of inositolphosphates. For the determination of the stimulus-induced changes in IP3 and its breakdown products (IP2 and IP1) cells were incubated in RPMI medium containing myo- $\left(2-{ }^{3} \mathrm{H}\right.$ inositol $)(1 \mu \mathrm{Ci} / \mathrm{ml})$ and $3 \%$ heat inactivated serum for $18 \mathrm{~h}$ as described by Di Virgilio et al. (5) in order to label phosphoinositides and inositolphosphates. The labeled cells (12 $\times 10^{6}$ cells for each condition) were washed twice at $37^{\circ} \mathrm{C}$ in RPMI medium without inositol. They were then resuspended in calcium medium and warmed to $37^{\circ} \mathrm{C}$ for $5 \mathrm{~min}$ and incubated with or without TPCK for $1 \mathrm{~min}$ followed by addition of FMLP for $20 \mathrm{~s}$. Incubations were terminated by addition of $10 \%(\mathrm{v} / \mathrm{v})$ trichloracetic acid and the samples were kept on ice and centrifuged thereafter. The supernatants were washed three times with a 5-fold excess of diethylether. The washed extract was adjusted to $\mathrm{pH} 7.5$ with Tris $0.2 \mathrm{M}$ and inositolphosphates separated by stepwise elution from Dowex (formate) columns as described (16). The radioactivity in the fractions was determined by liquid scintillation counting with $67 \%(\mathrm{v} / \mathrm{v})$ aquasol.

Measurement of cytosolic-free calcium. Free cytosolic calcium was determined in neutrophils loaded with the fluorescent dye quin2 as previously described (6).

Phosphorylation of proteins. Phosphorylation of neutrophil phosphoproteins was determined by incubating neutrophils with ${ }^{32} \mathrm{P}$ in a phosphate-free medium as previously described $(7,8)$. In brief, $2.5 \times 10^{7}$ neutrophils suspended in $4 \mathrm{ml}$ of phosphatefree calcium medium were incubated with $1 \mathrm{mCi}$ of ${ }^{32} \mathrm{P}$ for $2 \mathrm{~h}$ at $37^{\circ} \mathrm{C}$. The cells were then washed three times in phosphatefree medium and adjusted to a concentration of $2.5 \times 10^{6}$ cells/ ml. Aliquots of $1 \mathrm{ml}$ of cell suspension were warmed at $37^{\circ} \mathrm{C}$ for $5 \mathrm{~min}$ and the following conditions tested: stimulation of labeled cells with PMA $3 \times 10^{-8} \mathrm{M}$ for $5 \mathrm{~min}$; preincubation of cells with TPCK $10^{-5} \mathrm{M}$ for $4 \mathrm{~min}$; and incubation with PMA for $5 \mathrm{~min}$. Controls included incubation of cells with TPCK alone and with DMSO alone. The reaction was stopped by cooling on ice and simultaneous addition of trichloracetic acid $36 \%$ (v/v) $0.5 \mathrm{ml}$. After centrifugation, the supernatants were discarded and the pellets suspended in SDS-sample buffer $25 \mu \mathrm{l}$ (containing 1\% 2-mercaptoethanol, 2\% SDS, $80 \mathrm{mM}$ Tris- $\mathrm{HCl}$ pH $6.8,10 \%$ glycerol, and $0.05 \%$ bromophenolblue). The samples were boiled for $3 \mathrm{~min}$ and run on discontinuous slab gels with $5 \%$ acrylamide $(\mathrm{w} / \mathrm{v})$ in the running gel. Monitoring of molecular weights was performed with standard proteins of known molecular weights. Radiolabeled proteins were revealed by autoradiography with a Kodak X-omat S film with exposure at $-70^{\circ} \mathrm{C}$ for 4 days.

Statistical evaluation. The results are mean \pm SD and for comparisons, the Mann-Whitney test was used. The results represent the mean values of three experiments in triplicates, except for the phagocytic test for which samples were tested in duplicates.

\section{RESULTS}

Effect of TPCK on superoxide production. We first determined the lowest concentration of TPCK leading to inhibition of superoxide production in neutrophils stimulated with a particulate stimulus, opsonized Zymosan particles (12), and with FMLP $10^{-7} \mathrm{M}$. In the absence of TPCK, neutrophils stimulated with opsonized Zymosan particles produced $5.37 \pm 0.53 \mathrm{nmol} \mathrm{O}^{-} 2 /$ min $/ 10^{6}$ neutrophils. When preincubated with TPCK $10^{-5} \mathrm{M}$ for $1 \mathrm{~min}$, superoxide production was inhibited by $99 \%$. When the concentration of TPCK was lowered to $10^{-6} \mathrm{M}$, superoxide production was $3.42 \pm 0.53 \mathrm{nmol} / \mathrm{min} / 10^{6}$ neutrophils. Increasing the time of preincubation of cells with TPCK $10^{-6} \mathrm{M}$ resulted in a linear decrease of superoxide production, reaching an inhibition of superoxide production of $86 \%$ after 30 min preincubation. TPCK $10^{-5} \mathrm{M}$, when added to stimulated neutrophils at the moment of maximum superoxide production, led to cessation of superoxide production within $15 \mathrm{~s}$. These results indicate that TPCK inhibits superoxide production in a dose-dependent and time-dependent manner. Similar results were found, when FMLP was used as a stimulus. The superoxide production of neutrophils preincubated with TPCK $10^{-5} \mathrm{M}$ for $1 \mathrm{~min}$ was inhibited by $97 \%$.

It had been suggested, that the effect of TPCK on superoxide production could be due to unspecific inhibition of nonprotein sulfhydryl groups (17). This effect was obtained with much higher TPCK concentrations and longer preincubation periods and was shown to be reversible by incubation of neutrophils with glutathion (17). We thus determined the effect of reduced glutathion on the inhibition of superoxide production achieved with TPCK $10^{-5} \mathrm{M}$. When $10^{6}$ neutrophils preincubated with TPCK $10^{-5} \mathrm{M}$ for $5 \mathrm{~min}$ (which abolished superoxide production) were incubated with glutathion $10^{-3} \mathrm{M}$ for further 10 minutes, the superoxide production was $0.79 \pm 0.01 \mathrm{nmol} \mathrm{O}^{-}{ }_{2} / \mathrm{min}$, which corresponded to $16 \%$ of the superoxide production of untreated cells. When TPCK-treated cells were washed three times before incubation with glutathion under similar conditions, the results were identical to those in unwashed cells. All further experiments were therefore performed in cells preincubated with TPCK $10^{-5} \mathrm{M}$ for $1 \mathrm{~min}$, i.e. under conditions in which reduced glutathion did not release the almost total inhibition of superoxide production by TPCK. 
Effect of TPCK on the release of specific and azurophile granules. The release of specific and azurophile granules by neutrophils stimulated with FMLP was measured with and without preincubation of neutrophils with TPCK $10^{-5}$ for $1 \mathrm{~min}$. Specific granule release, measured by released vitamin $\mathrm{B}_{12}$ binding protein was $19.8 \pm 1.2 \%$. Inhibition of specific granule release was $34 \%$. The release of azurophile granules measured by the release of $\beta$ glucuronidase was $13.6 \pm 1 \%$ in these experiments (cells were not preincubated with cytochalasin B before stimulation). Inhibition of azurophile granule release by TPCK was $46 \%$.

Effect of TPCK $10^{-5} \mathrm{M}$ on generation of IP3 after stimulation of cells with FMLP (Table 1). Since IP3 generated by receptor activation of phospholipase $\mathrm{C}$ is thought to function as a second messenger $(4,5)$ we also determined the generation of IP3 and its degradation products, IP2 and IP1, in neutrophils stimulated with FMLP $10^{-7} \mathrm{M}$, with and without preincubation of cells with TPCK $10^{-5} \mathrm{M}$ for $1 \mathrm{~min}$. The results are expressed in percent of basal values, which correspond to the radioactivity of fractions of unstimulated cells (Table 1). In control neutrophils stimulated with FMLP $10^{-7} \mathrm{M}$ IP3 levels rose to $269 \pm 16 \%$ of basal levels within $20 \mathrm{~s}$. These results were similar to those obtained with neutrophils preincubated with TPCK $(244 \pm 11 \%)$. Since recently, pertussis toxin was shown to abolish the FMLP-induced generation of IP3 in neutrophils (4), we used pertussis toxin as a control. Preincubation of cell with $250 \mathrm{ng} / \mathrm{m}$ of pertussis toxin before stimulation of neutrophils with FMLP abolished the FMLP-induced rise in IP3.

Effect of TPCK $10^{-5} \mathrm{M}$ on FMLP stimulated membrane depolarization, rise of free cytosolic calcium, and release of intra-

Table 1. Effect of TPCK $10^{-5} \mathrm{M}$ on generation of IP3, IP2, and IPI in neutrophils stimulated with FMLP $10^{-6} M^{*}$

\begin{tabular}{lccc}
\hline & IP3 & IP2 & IP1 \\
\hline Unstimulated neutrophils & $100 \pm 2 \%$ & $100 \pm 3 \%$ & $100 \pm 2 \%$ \\
Stimulated neutrophils & $269 \pm 16 \%$ & $183 \pm 10 \%$ & $215 \pm 15 \%$ \\
Stimulated neutrophils & $244 \pm 11 \%$ & $186 \pm 11 \%$ & $205 \pm 9 \%$ \\
$\quad$ preincubated with & & & \\
$\quad$ TPCK $10^{-5} \mathrm{M}$ \\
$\begin{array}{l}\text { Stimulated neutrophils } \\
\text { preincubated with Per- }\end{array}$ & $110 \pm 3 \%$ & $99 \pm 5 \%$ & $103 \pm 3 \%$ \\
tussis toxin 250 ng/ml & & & \\
\hline & Preincubation of cells with inhibitors was 1 min for TPCK and 2 h \\
for Pertussis toxin (250 ng/ml) followed by FMLP for 20 s. Results are \\
percent dpm of basal values in the corresponding fraction. Results are \\
mean \pm SD.
\end{tabular}

cellular calcium stores (Fig. 1). The membrane depolarization which follows stimulation of neutrophils with FMLP $10^{-7} \mathrm{M}$ is shown in Figure $1 A$ in neutrophils preincubated with TPCK $10^{-5}$ $\mathrm{M}$ as well as control neutrophils. Both curves are identical. The increase in free cytosolic calcium in calcium medium (Fig. $1 B$ ) and the release of intracellular calcium stores in the absence of extracellular calcium (Fig. 1C) on stimulation of cells with FMLP $10^{-7} \mathrm{M}$ were also identical when cells preincubated with TPCK $10^{-5} \mathrm{M}$ were compared to control cells.

When neutrophils were preincubated with higher concentrations of TPCK $\left(10^{-4} \mathrm{M}\right)$, the membrane depolarization as well as the rise in free cytosolic calcium were inhibited significantly. As a control, the superoxide production of quin2 loaded cells (control or preincubated with TPCK $10^{-5} \mathrm{M}$ ) was also determinated in parallel with the same batch of cells. In these cells, superoxide production was totally abolished by preincubation with TPCK $10^{-5} \mathrm{M}$.

Effect of TPCK $10^{-5} \mathrm{M}$ on PMA-stimulated phosphorylation of neutrophil proteins (Fig. 2). We tested the effect of preincubation of neutrophils with TPCK $10^{-5}$ on phosphorylation in neutrophils labeled with ${ }^{32} \mathrm{P}$ and stimulated with PMA $10^{-7} \mathrm{M}$. As shown in Figure 2, six new protein bands appeared in neutrophils stimulated with PMA and one band disappeared after stimulation in comparison to unstimulated cells. After preincubation with TPCK $10^{-5} \mathrm{M}$ prior to stimulation, the same pattern of newly phosphorylated bands as in stimulated cells was observed and the same band disappeared. Thus, TPCK at the used concentration did not interfere with PMA-induced protein phosphorylation.

Effect of TPCK on phagocytosis and bactericidal activity of neutrophils (Fig. 3). In order to exclude an unspecific effect of TPCK $10^{-5} \mathrm{M}$ on cell function, we performed a phagocytic assay (12) in the presence and absence of TPCK $10^{-5} \mathrm{M}$. Whereas the ingestion of endotoxin coated ORO particles was $88 \pm 6 \%$ of that of control cells ( $p=\mathrm{NS}$ ), the killing of $S$. aureus strain Wood 46 was only $11 \pm 2 \%$ of that achieved in control cells ( $p$ $<0.01$ ). These results show that preincubation of neutrophils with TPCK $10^{-5} \mathrm{M}$ significantly inhibits bactericidal activity on $S$ aureus, whereas the complement mediated phagocytosis was not affected.

\section{DISCUSSION}

In this study we showed that when neutrophils were preincubated with TPCK $10^{-5} \mathrm{M}$ and stimulated with FMLP (or opsonized zymosan as a particulate stimulus), the superoxide production was completely inhibited. We then performed various ex-
A
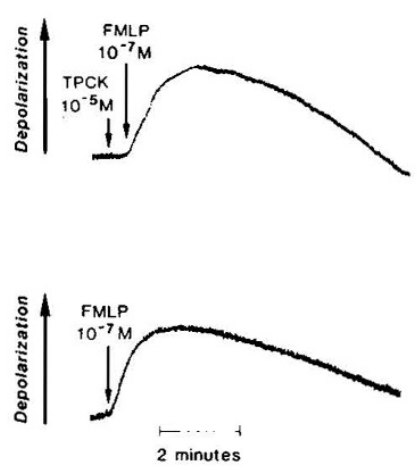
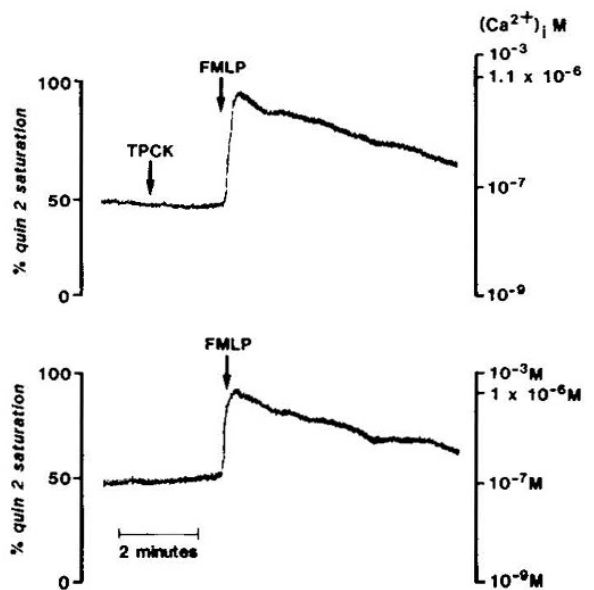

C
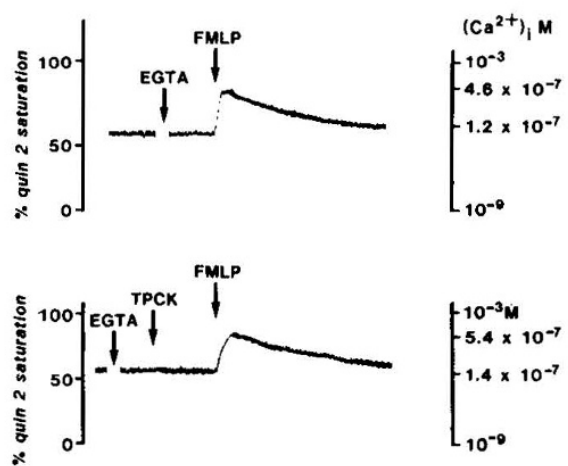

Fig. 1. Effect of preincubation of neutrophils with TPCK $10^{-5} \mathrm{M}$ on the FMLP-induced membrane depolarization assessed with the fluorescent dye di-0-C5 (3) according to Seligman et al. (9) ( $A$ ), the FMLP-induced calcium transient in a calcium containing buffer $(B)$, and the FMLP-induced release of intracellular calcium stores $(C)$ assessed in neutrophils loaded with quin 2 as previously described $(6,11)$. Figure 1 shows a representative curve of three experiments performed in triplicates. 


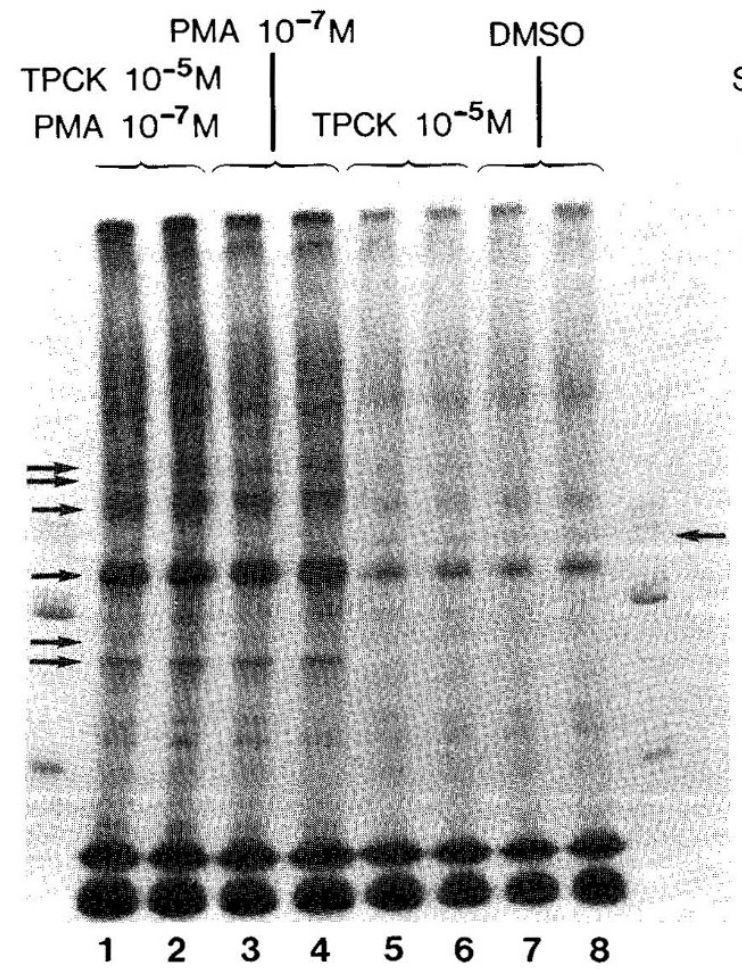

Standard

proteins

$200^{\prime} 000$

$116^{\prime} 500$

$92^{\prime} 500$

$45^{\prime} 000$

$41^{\prime} 000$

$14^{\prime} 000$

Fig. 2. Autoradiography of ${ }^{32} \mathrm{P}$-labeled neutrophil proteins separated by molecular weights with polyacrylamide-gel-electrophoresis. The molecular weights of standards run simultaneously are indicated on the right of Figure 2. Lanes 1-4 phosphorylated proteins of neutrophils stimulated with PMA; lanes 1 and 2, cells preincubated with TPCK $10^{-5} \mathrm{M}$ for 1 min before stimulation with PMA. Lanes 5-8, phosphorylated proteins of unstimulated control cells. Lanes 5 and 6, cells preincubated with TPCK. Arrows on the left indicate newly phosphorylated proteins in stimulated cells, and the arrow at the right indicates one protein band that disappears in stimulated cells.

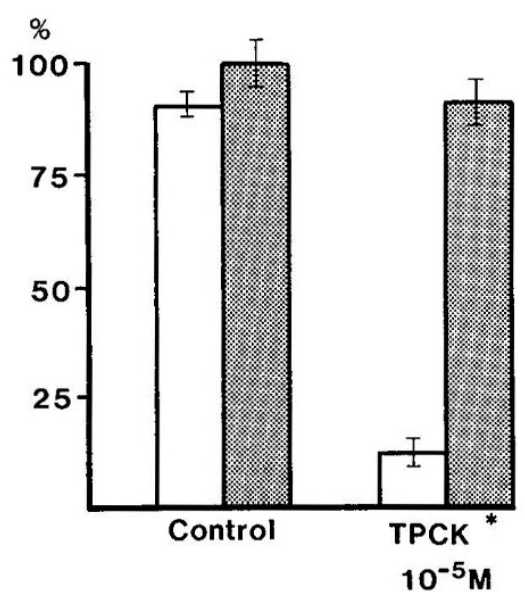

Fig. 3. Effect of preincubation of neutrophils with TPCK $10^{-5} \mathrm{M}$ for $5 \mathrm{~min}$ on the ingestion rate of endotoxin-coated ORO particles (shaded bars) (14) and the phagocytic-bactericidal activity (12) on $S$. aureus Wood 46. The results correspond to mean $\pm \mathrm{SD}$ of three separate experiments (in duplicates for the ingestion rate ORO particles and in triplicates for the bactericidal activity or $S$. aureus). The ingestion rate of control cells was considered as $100 \%$ and the bactericidal activity is expressed in percent killing of $S$. aureus Wood 46 by neutrophils.

periments to detect and quantify the levels of second messengers in neutrophils stimulated with the chemotactic peptide FMLP in the presence or absence of TPCK. These experiments showed that the enzyme(s) inhibited by TPCK were not involved in the following. 1) FMLP-induced activation of phospholipase C, which we assessed by measuring IP3 production (Table 1). 2) FMLP-induced membrane depolarization (Fig. $1 A$ ), an early event in cell activation which follows receptor stimulation (9). 3) FMLP-induced $\mathrm{Ca}^{++}$influx from the extracellular medium (Fig. $1 B$ ) and release of calcium from intracellular calcium stores (Fig. 1C). 4) PMA-stimulated protein phosphorylation (Fig. 2) which is thought to be mediated by the activation of protein kinase $\mathrm{C}$ $(8,9,20)$.

Thus, the step at which TPCK inhibits superoxide production must be distal to the rise in intracellular calcium and protein phosphorylation, two second messengers required to initiate cell function $(6,7,8,11)$.

Results from a previous study on inhibition by TPCK of membrane potential changes and degranulation in rat neutrophils had suggested that the TPCK-inhibited step was located in the early events following cell stimulation. In that study by Duque et al. (18) the membrane potential changes assessed by a slightly different fluorescent probe were inhibited by TPCK $10^{-5}$ M. The authors also found that increasing the extracellular calcium concentration could overcome the inhibition of membrane potential changes by TPCK $10^{-5} \mathrm{M}$ and they concluded that the TPCK-inhibited step preceded a calcium-dependent step. Since in the studies by Duque et al. (18) and Mackin and Becker (19) the inhibition of membrane potential changes by TPCK was dose dependent, it is conceivable that interspecies differences between rat and human neutrophils as well as the use of a slightly different fluorescent probe may explain the observed difference. In human neutrophils, we found that at a 10 -fold higher concentration, TPCK also significantly inhibited phagocytosis, membrane potential changes, and the FMLP-induced rise in free cytosolic calcium. According to Tsan (17), the unspecific inhibition of human neutrophil sulfhydryl groups becomes significant at concentrations above $10^{-5} \mathrm{M}$, but it may well be that in rat neutrophils the concentration at which TPCK has unspecific effects is lower.

Another study on rabbit neutrophils showed that after preincubation of rabbit neutrophils with TPCK $2.5 \pm 10^{-5} \mathrm{M}$ the number of FMLP receptors decreased and simultaneously the affinity of the receptors for FMLP increased (19). If in our experiments with human neutrophils TPCK $10^{-5} \mathrm{M}$ had an effect on FMLP receptors, this effect did not interfere with second messenger generation.

As mentioned above, TPCK at high concentration has unspecific effects on neutrophil sulfhydryl groups (17). To determine whether nonspecific toxic effects of TPCK were responsible for inhibition of superoxide production, we tested the effect of TPCK $10^{-5} \mathrm{M}$ on complement-mediated phagocytosis (14) and complement-mediated killing of $S$. aureus (13) by human neutrophils (Fig. 3). The phagocytosis of complement-coated ORO particles was unaffected, whereas the killing of $S$. aureus, which is known to be mediated by superoxide production (1), was significantly inhibited. These results indicate that under conditions leading to complete inhibition of superoxide production, the cells were able to phagocyte normally and thus at the concentration of $10^{-5} \mathrm{M}$ TPCK was devoid of unspecific side effects. In addition, reduced glutathion, which was shown to reverse the unspecific effects of TPCK on human neutrophils (17) had no significant effect on the inhibition of superoxide production by TPCK $10^{-5} \mathrm{M}$.

We also observed a partial inhibition of granule release in neutrophils preincubation with TPCK $10^{-5} \mathrm{M}$. From our data we cannot conclude, if the mechanism, by which TPCK inhibits superoxide production and granule release is the same or if it is different.

In summary we conclude that the step at which TPCK $10^{-5}$ $M$ inhibited superoxide production is located at a site distal from calcium mobilization and protein phosphorylation, both events required for the activation of the oxidative system. The events distal to calcium mobilization and the nature of the proteins phosphorylated by protein kinase $\mathrm{C}$ are presently poorly understood. Recently, it has been shown that botulinic toxin is capable 
of inhibiting exocytosis at cytosolic calcium concentrations that trigger exocytosis (20). Thus TPCK, botulinic toxin, and hopefully other probes will be useful tools to study the effector system in cellular activation. Also, a novel serine-esterase expressed by cytotoxic $\mathrm{T}$ lymphocytes was recently revealed by using a radiolabeled protease inhibitor (21). Since TPCK at $10^{-5} \mathrm{M}$ selectively inhibits the oxidative system, whose components are thought to be located in at least two cellulars compartments $(22,23)$, it is possible that this compound synthesized with radiolabeled precursors may be a useful tool to localize the chymotrypsin-like enzymatic activity that is thought to be involved in the activation of the oxidase.

Acknowledgment. Ionomycin was a gift from Dr. C. M. Hlin, Hoffmann-LaRoche Inc., Nutley, NJ.

\section{REFERENCES}

1. Babior BM 1984 Oxidants from phagocytes: agents of defense and destruction Blood 64:959-966

2. Grady PG, Todd Davis A, Shapira E 1979 The effect of some protease substrates and inhibitors on chemotaxis and protease activity of human polymorphonuclear leucocytes. J Infect Dis 140:999-1003

3. Kitagawa S. Takaku F, Sakomoto S 1980 Evidence that proteases are involved in superoxide production by human polymorphonuclear leucocytes. J Clin Invest 65:74-81

4. Krause KH, Schlegel W, Wolheim CB, Anderson T, Waldvogel FA, Lew PD 1985 Chemotactic peptide activation of human neutrophils and HL60 cells. Pertussis toxin reveals correlation between inositoltrisphosphate generation, calcium ion transients and cellular activation. J Clin Invest 76:1348-1354

5. Di Virgilio F, Vincentini LM, Treves S, Riz G, Pozzan T 1985 Inositolphosphate formation in fMet-Leu-Phe stimulated human neutrophils does not require an increase in the cytosolic free $\mathrm{Ca}++$ concentration. Biochem $\mathrm{J}$ 229:361-367

6. Pozzan $T$, Lew PD, Wolheim CB, Tsien RY 1983 Is cytosolic free calcium regulating neutrophil activation? Science 221:1413-1415

7. Schneider C, Zanetti M, Romeo D 1981 Surface reactive stimuli selectively increase protein phosphorylation in human neutrophils. FEBS Lett 127:4-8

8. Andrews PC, Babior BM 1983 Endogenous protein phosphorylation by resting and activated human neutrophils. Blood 61:333-340

9. Seligman BE, Gallin EK, Martin DL, Shain W, Gallin JI 1980 Interaction of chemotactic factors with human polymorphonuclear leucocytes: studies using a membrane potential sensitive cyanine dye. J Membr Biol 53:257-272

10. Boyüm A 1976 Isolation of lymphocytes, granulocytes and macrophages. Scand J Immunol 5:9-15

11. Lew PD, Wollheim CB, Waldvogel FA, Pozzan T 1984 Modulation of cytosolic-free calcium transients by changes in intracellular calcium-buffering capacity: correlation with exocytosis and $\mathrm{O}_{2}^{-}$production in human neutrophils. J Cell Biol 99:1212-1220

12. Zimmerli W, Lew PD, Waldvogel FA 1984 Pathogenesis of foreign body infection: evidence for a local granulocyte defect. J Clin Invest 73:11911200

13. Lew PD, Zubler R, Vaudaux P, Farquet JJ, Waldvogel FA, Lambert PH 1979 Decreased heat-labile opsonic activity and complement levels associated with evidence of $\mathrm{C} 3$ breakdown products in infected pleural effusions. J Clin Invest 63:326-334

14. Stossel TP 1973 Evaluation of opsonic and leucocyte function with a spectrophotometric test in patients with infection and with phagocytic disorders. Blood 42:121-130

15. Dewald B, Bretz U, Baggiolini M 1982 Release of gelatinase from a novel secretory compartment of human neutrophils. J Clin Invest 70;518-525

16. Berridge MJ, Dawson RMC, Downes CP, Heslop JP, Irvine RF 1983 Changes in the levels of inositolphosphate after agonist dependent hydrolysis of membrane phosphoinositides. Biochem J 212:473-482

17. Tsan MF 1983 Inhibition of neutrophil sulfhydryl groups, by chloromethylketones. A mechanism for their inhibition of superoxide production Biochem Biophys Res Commun 112:671-677

18. Duque RE, Sem HPh, Sulavik MC, Ward PE 1983 Inhibition by tosyl-L phenylalanyl chloromethylketone of membrane potential changes in rat neutrophils. J Biol Chem 258:8123-8128

19. Mackin WM, Becker EL 1983 The formylpeptide chemotactic receptor on rabbit peritoneal neutrophils: change of receptor affinity and number by $L-$ 1-tosylamide-2-phenylethyl-chloromethylketone (TPCK). Int J Immunopharmacol 5:365-375

20. Knight PE, Tonge DA, Baker PF 1985 Inhibition of exocytosis in bovine adrenal medullary cells by botulinum toxin type D. Nature 317:719-721

21. Pasternack MS, Eisen HN 1985 A novel serine esterase expressed by cytotoxic T lymphocytes. Nature 314:743-745

22. Borregard M, Tauber AI 1984 Subcellular localization of the human neutrophil NADPH oxidase b-cytochrome and associated flavoprotein. $J$ Biol Chem 259:47-52

23. Boxer GJ, Curnutte JT, Boxer LA 1985 Physiology in medicine: polymorphonuclear leucocyte function. Hosp Pract 20:69-90 